\title{
Multimorbidity and adverse events of special interest associated with CoronaVac (Sinovac) and Comirnaty (Pfizer- BioNTech)
}

\author{
Francisco Lai \\ The University of Hong Kong https://orcid.org/0000-0002-9121-1959 \\ Lei Huang \\ The University of Hong Kong \\ Celine Sze Ling Chui \\ The University of Hong Kong \\ Eric Wan \\ University of Hong Kong \\ Xue Li \\ The University of Hong Kong \\ Carlos King Ho Wong \\ University of Hong Kong https://orcid.org/0000-0002-6895-6071 \\ Edward Wai Wa Chan \\ The University of Hong Kong \\ Tiantian Ma \\ The University of Hong Kong

\section{Dawn Hei Lum} \\ The University of Hong Kong \\ Janice Ching Nam Leung \\ The University of Hong Kong

\section{Hao Luo} \\ The University of Hong Kong

\section{Esther Wai Yin Chan} \\ The University of Hong Kong \\ lan Wong ( $\square$ wongick@hku.hk) \\ University of Hong Kong https://orcid.org/0000-0001-8242-0014
}

Article

Keywords: multimorbidity, Coronavac, Pfizer-BioNTech, COVID-19, vaccination

Posted Date: September 20th, 2021

DOl: https://doi.org/10.21203/rs.3.rs-880508/v1

License: (c) (i) This work is licensed under a Creative Commons Attribution 4.0 International License. Read Full License

Version of Record: A version of this preprint was published at Nature Communications on January 20th, 2022. See the published version at https://doi.org/10.1038/s41467-022-28068-3. 


\section{Abstract}

We examined the potential additional risk of adverse events of special interest (AESI) within 28 days post-Covid-19 vaccination with CoronaVac or Comirnaty (Pfizer-BioNTech) imposed by multimorbidity ( $2^{+}$chronic conditions). Using a territory-wide public healthcare database with linkage to population-based vaccination records in Hong Kong, we conducted a retrospective cohort study of patients with chronic diseases. Thirty AESI according to World Health Organization's Global Advisory Committee on Vaccine Safety were examined. In total, 883,416 patients were included. During follow-up, 2,807 (0.3\%) patients had AESI. Weighted Cox models suggested that vaccinated patients had lower risks of any AESI than those unvaccinated, that multimorbidity was associated with an increased risk regardless of vaccination status, and there was no significant effect modification of the association of vaccination with AESI by multimorbidity status. To conclude, we found no evidence that multimorbidity imposes extra risks of AESI within 28 days following Covid-19 vaccination.

\section{Introduction}

The safety profile of Covid-19 vaccines is of great public health concern and is crucial to tackling vaccine hesitancy amidst the pandemic, especially in countries where the SARS-CoV- 2 infection rate is relatively well controlled ${ }^{1}$. In particular, there have been widespread speculations of cardiovascular and other adverse events of special interest (AESI) in relation to Covid-19 vaccines 2,3 . This may be due to thromboembolic safety signals ${ }^{4,5}$ and case reports of other adverse outcomes, such as Bell's palsy ${ }^{6,7}$ following the administration of specific vaccine types.

There is also increased concern regarding the vaccination of people living with chronic conditions and multimorbidity, commonly referred to as the co-occurrence of two or more chronic health conditions in an individual ${ }^{8}$. Previous research before the pandemic has shown a potential risk increase of cardiovascular events and other adverse outcomes in people living with multimorbidity compared with those without ${ }^{9,10}$. Nonetheless, it is currently unclear if multimorbidity is related to a risk increase of any AESI following Covid-19 vaccination. Existing research comparing the relationship between vaccination and AESI across sub-populations with and without multimorbidity is limited. Therefore, AESI in populations living with multimorbidity requiring long-term care largely remain to be investigated ${ }^{11,12}$.

Hong Kong is one of the relatively few jurisdictions in the world that has approved and rolled out the widespread emergency use of both CoronaVac (Sinovac) ${ }^{13}$ and Comirnaty (Fosun-BioNTech, equivalent to Pfizer-BioNTech outside China) ${ }^{14}$ Covid-19 vaccines ${ }^{15}$. We analyzed the territory-wide public healthcare databases linked with population-based vaccination records from the Government to examine the risk of AESI of these two vaccines. This study aims to examine the relationship between Covid19 vaccination and AESI among patients with chronic disease in Hong Kong and the potential additional AESI risk following vaccination associated with multimorbidity.

\section{Results}

As shown in Fig. 1, among 3,983,529 patients who used Hospital Authority (HA) care services, 1,643,419 (41.3\%) were vaccinated (at least one dose). 1,391,033 patients were identified as having at least one diagnosis of any of the 20 listed chronic conditions. After age- and sex-matching for the mapping of the index date from the vaccinated to the unvaccinated group, 1,184,476 patients remained. Eventually, 883,416 patients were adopted as the final cohort with $38.0 \%$ of the patients vaccinated, after a further removal of ineligible patients. The median follow-up time (interquartile range) for the CoronaVac $(n=$ $182,442)$, Comirnaty $(n=153,178)$, and unvaccinated groups $(n=547,796)$ were $28(23-28), 21(20-22), 28(21-28)$ days respectively.

\section{Cohort characteristics}

Table 1 shows the cohort characteristics before and after weighting. The unvaccinated group had the highest mean age of 62.11 [(standard deviation (SD): 12.85] followed by 61.58 (SD: 11.08) among the CoronaVac group and 56.81 (SD:13.43) among the Comirnaty group. There were higher proportions of men in the vaccinated groups ( $48.7 \%$ for CoronaVac; $47.4 \%$ for 
Comirnaty) compared with the unvaccinated group (41.9\%). For all three groups, the most prevalent condition was hypertension (67.1\% for unvaccinated group; $68.7 \%$ for CoronaVac; $60.9 \%$ for Comirnaty), followed by diabetes (type 2 ) (33.0\% for unvaccinated group; $28.1 \%$ for CoronaVac; $23.8 \%$ for Comirnaty), and severe constipation ( $8.3 \%$ for unvaccinated group; $9.0 \%$ for CoronaVac; $9.0 \%$ for Comirnaty). After weighting the maximum standardized mean differences (SMD) for all covariates were all smaller than 0.1 . 
Table 1

Unweighted and weighted cohort characteristics $(\mathrm{N}=883,416)$ of unvaccinated individuals, CoronaVac or Comirnaty recipients

\begin{tabular}{|c|c|c|c|c|c|c|c|}
\hline & \multicolumn{3}{|l|}{ Unweighted } & \multicolumn{4}{|l|}{ Weighted } \\
\hline & Unvaccinated & CoronaVac & Comirnaty & Unvaccinated & CoronaVac & Comirnaty & \\
\hline $\mathrm{n}$ & 547796 & 182442 & 153178 & 536072 & 124524 & 96322 & $\begin{array}{l}\text { Maximum } \\
\text { weighted } \\
\text { SMD }\end{array}$ \\
\hline $\begin{array}{l}\text { Age [mean } \\
(\mathrm{SD})]\end{array}$ & $62.11(12.85)$ & $\begin{array}{l}61.58 \\
(11.08)\end{array}$ & $\begin{array}{l}56.81 \\
(13.43)\end{array}$ & 61.08 (13.33) & $\begin{array}{l}61.08 \\
(11.31)\end{array}$ & $\begin{array}{l}61.08 \\
(12.17)\end{array}$ & $<0.001$ \\
\hline Sex: male (\%) & $\begin{array}{l}229791 \\
(41.9)\end{array}$ & $\begin{array}{l}88881 \\
(48.7)\end{array}$ & $\begin{array}{l}72586 \\
(47.4)\end{array}$ & $\begin{array}{l}242587.9 \\
(44.3)\end{array}$ & $\begin{array}{l}80814.1 \\
(44.3)\end{array}$ & $\begin{array}{l}67831.5 \\
(44.3)\end{array}$ & $<0.001$ \\
\hline \multicolumn{8}{|l|}{$\begin{array}{l}\text { Chronic } \\
\text { conditions (\%) }\end{array}$} \\
\hline Hypertension & $\begin{array}{l}367799 \\
(67.1)\end{array}$ & $\begin{array}{l}125314 \\
(68.7)\end{array}$ & $\begin{array}{l}93319 \\
(60.9)\end{array}$ & $\begin{array}{l}363621.4 \\
(66.4)\end{array}$ & $\begin{array}{l}121104.0 \\
(66.4)\end{array}$ & $\begin{array}{l}101688.5 \\
(66.4)\end{array}$ & $<0.001$ \\
\hline $\begin{array}{l}\text { Diabetes (Type } \\
\text { 2) }\end{array}$ & $\begin{array}{l}180875 \\
(33.0)\end{array}$ & $\begin{array}{l}51312 \\
(28.1)\end{array}$ & $\begin{array}{l}36403 \\
(23.8)\end{array}$ & $\begin{array}{l}166524.0 \\
(30.4)\end{array}$ & $\begin{array}{l}55471.7 \\
(30.4)\end{array}$ & $\begin{array}{l}46570.1 \\
(30.4)\end{array}$ & $<0.001$ \\
\hline $\begin{array}{l}\text { Severe } \\
\text { constipation }\end{array}$ & 45405 (8.3) & $\begin{array}{l}16424 \\
(9.0)\end{array}$ & $\begin{array}{l}13804 \\
(9.0)\end{array}$ & 46915.4 (8.6) & $\begin{array}{l}15619.6 \\
(8.6)\end{array}$ & $\begin{array}{l}13111.6 \\
(8.6)\end{array}$ & $<0.001$ \\
\hline Depression & $34333(6.3)$ & $\begin{array}{l}10745 \\
(5.9)\end{array}$ & $\begin{array}{l}13310 \\
(8.7)\end{array}$ & $36257.6(6.6)$ & $\begin{array}{l}12056.4 \\
(6.6)\end{array}$ & $\begin{array}{l}10126.4 \\
(6.6)\end{array}$ & $<0.001$ \\
\hline Cancer & 31308 (5.7) & $4671(2.6)$ & $4733(3.1)$ & $25244.0(4.6)$ & $\begin{array}{l}8407.6 \\
(4.6)\end{array}$ & $\begin{array}{l}7050.6 \\
(4.6)\end{array}$ & $<0.001$ \\
\hline Hypothyroidism & $27752(5.1)$ & $9555(5.2)$ & $9508(6.2)$ & 29019.7 (5.3) & $\begin{array}{l}9673.0 \\
(5.3)\end{array}$ & $\begin{array}{l}8119.2 \\
(5.3)\end{array}$ & $<0.001$ \\
\hline Chronic pain & 23305 (4.3) & 7577 (4.2) & $7845(5.1)$ & $24013.3(4.4)$ & $\begin{array}{l}8006.3 \\
(4.4)\end{array}$ & $\begin{array}{l}6699.9 \\
(4.4)\end{array}$ & $<0.001$ \\
\hline Asthma & $18172(3.3)$ & $5119(2.8)$ & $7061(4.6)$ & $18773.8(3.4)$ & $\begin{array}{l}6277.3 \\
(3.4)\end{array}$ & $\begin{array}{l}5265.2 \\
(3.4)\end{array}$ & $<0.001$ \\
\hline $\begin{array}{l}\text { Chronic } \\
\text { pulmonary } \\
\text { disease }\end{array}$ & $12090(2.2)$ & $2638(1.4)$ & $1663(1.1)$ & $10152.9(1.9)$ & $\begin{array}{l}3373.7 \\
(1.8)\end{array}$ & $\begin{array}{l}2846.7 \\
(1.9)\end{array}$ & $<0.001$ \\
\hline Schizophrenia & 10915 (2.0) & $1634(0.9)$ & $1637(1.1)$ & 8803.3 (1.6) & $\begin{array}{l}2930.7 \\
(1.6)\end{array}$ & $\begin{array}{l}2463.7 \\
(1.6)\end{array}$ & $<0.001$ \\
\hline $\begin{array}{l}\text { Rheumatoid } \\
\text { arthritis }\end{array}$ & 7654 (1.4) & $1582(0.9)$ & $1663(1.1)$ & $6783.9(1.2)$ & $\begin{array}{l}2257.3 \\
(1.2)\end{array}$ & $\begin{array}{l}1883.2 \\
(1.2)\end{array}$ & $<0.001$ \\
\hline $\begin{array}{l}\text { Peptic ulcer } \\
\text { disease }\end{array}$ & $6662(1.2)$ & $2224(1.2)$ & $1583(1.0)$ & $6502.3(1.2)$ & $\begin{array}{l}2162.0 \\
(1.2)\end{array}$ & $\begin{array}{l}1810.1 \\
(1.2)\end{array}$ & $<0.001$ \\
\hline Alcohol misuse & $4535(0.8)$ & $1356(0.7)$ & $1278(0.8)$ & $4441.6(0.8)$ & $\begin{array}{l}1468.2 \\
(0.8)\end{array}$ & $\begin{array}{l}1242.3 \\
(0.8)\end{array}$ & $<0.001$ \\
\hline Cirrhosis & $3294(0.6)$ & $544(0.3)$ & $433(0.3)$ & $2634.9(0.5)$ & $876.7(0.5)$ & $\begin{array}{l}746.0 \\
(0.5)\end{array}$ & $<0.001$ \\
\hline $\begin{array}{l}\text { Parkinson's } \\
\text { disease }\end{array}$ & $3182(0.6)$ & $409(0.2)$ & $336(0.2)$ & $2419.1(0.4)$ & $811.4(0.4)$ & $\begin{array}{l}685.1 \\
(0.4)\end{array}$ & $<0.001$ \\
\hline Dementia & $3030(0.6)$ & $299(0.2)$ & $204(0.1)$ & $2184.8(0.4)$ & $734.9(0.4)$ & $\begin{array}{l}607.3 \\
(0.4)\end{array}$ & 0.001 \\
\hline Psoriasis & $2524(0.5)$ & $721(0.4)$ & $814(0.5)$ & $2513.0(0.5)$ & $836.6(0.5)$ & $\begin{array}{l}705.5 \\
(0.5)\end{array}$ & $<0.001$ \\
\hline
\end{tabular}




\begin{tabular}{|c|c|c|c|c|c|c|c|}
\hline & Unweighted & & & Weighted & & & \\
\hline $\begin{array}{l}\text { Irritable bowel } \\
\text { syndrome }\end{array}$ & $1710(0.3)$ & $621(0.3)$ & $823(0.5)$ & $1960.3(0.4)$ & $652.3(0.4)$ & $\begin{array}{l}545.5 \\
(0.4)\end{array}$ & $<0.001$ \\
\hline $\begin{array}{l}\text { Inflammatory } \\
\text { bowel disease }\end{array}$ & $1548(0.3)$ & $360(0.2)$ & $595(0.4)$ & $1584.6(0.3)$ & $514.3(0.3)$ & $\begin{array}{l}427.3 \\
(0.3)\end{array}$ & 0.002 \\
\hline $\begin{array}{l}\text { Peripheral } \\
\text { vascular } \\
\text { disease }\end{array}$ & $93(0.0)$ & $9(0.0)$ & $9(0.0)$ & $91.5(0.0)$ & $8.7(0.0)$ & $13.9(0.0)$ & 0.012 \\
\hline $\begin{array}{l}\text { Multimorbidity } \\
\text { status }^{\mathrm{a}}(\%)\end{array}$ & & & & & & & 0.012 \\
\hline Monomorbid & $\begin{array}{l}344866 \\
(63.0)\end{array}$ & $\begin{array}{l}128890 \\
(70.6)\end{array}$ & $\begin{array}{l}114311 \\
(74.6)\end{array}$ & $\begin{array}{l}363464.1 \\
(66.4)\end{array}$ & $\begin{array}{l}121971.7 \\
(66.9)\end{array}$ & $\begin{array}{l}102332.2 \\
(66.8)\end{array}$ & - \\
\hline Two conditions & $\begin{array}{l}168166 \\
(30.7)\end{array}$ & $\begin{array}{l}46844 \\
(25.7)\end{array}$ & $\begin{array}{l}34071 \\
(22.2)\end{array}$ & $\begin{array}{l}155986.2 \\
(28.5)\end{array}$ & $\begin{array}{l}51013.4 \\
(28.0)\end{array}$ & $\begin{array}{l}42906.3 \\
(28.0)\end{array}$ & - \\
\hline $\begin{array}{l}\text { Three } \\
\text { conditions }\end{array}$ & 28767 (5.3) & 5893 (3.2) & $4224(2.8)$ & $23974.7(4.4)$ & $\begin{array}{l}7938.7 \\
(4.4)\end{array}$ & $\begin{array}{l}6712.3 \\
(4.4)\end{array}$ & - \\
\hline $\begin{array}{l}\text { Four or more } \\
\text { conditions }\end{array}$ & $5997(1.1)$ & $815(0.4)$ & $572(0.4)$ & $4371.0(0.8)$ & $\begin{array}{l}1518.2 \\
(0.8)\end{array}$ & $\begin{array}{l}1227.3 \\
(0.8)\end{array}$ & - \\
\hline \multicolumn{8}{|l|}{$\begin{array}{l}\text { Adverse events } \\
\text { of special } \\
\text { interest }^{\mathrm{a}}(\%)\end{array}$} \\
\hline $\begin{array}{l}\text { Cardiovascular } \\
\text { system }\end{array}$ & $759(0.1)$ & $160(0.1)$ & $106(0.1)$ & $737.8(0.1)$ & $158.1(0.1)$ & $\begin{array}{l}118.0 \\
(0.1)\end{array}$ & - \\
\hline $\begin{array}{l}\text { Circulatory } \\
\text { system }\end{array}$ & $689(0.1)$ & $135(0.1)$ & $113(0.1)$ & $664.4(0.1)$ & $131.6(0.1)$ & $\begin{array}{l}134.3 \\
(0.1)\end{array}$ & - \\
\hline $\begin{array}{l}\text { Hepato-renal } \\
\text { system }\end{array}$ & $513(0.1)$ & $148(0.1)$ & $86(0.1)$ & $508.3(0.1)$ & $147.9(0.1)$ & $85.7(0.1)$ & - \\
\hline $\begin{array}{l}\text { Auto immune } \\
\text { diseases }\end{array}$ & $229(0.0)$ & $40(0.0)$ & $55(0.0)$ & $233.5(0.0)$ & $41.3(0.0)$ & $50.6(0.0)$ & - \\
\hline $\begin{array}{l}\text { Respiratory } \\
\text { system }\end{array}$ & $154(0.0)$ & $18(0.0)$ & $10(0.0)$ & $140.9(0.0)$ & $17.9(0.0)$ & $12.9(0.0)$ & - \\
\hline Other system & $113(0.0)$ & $42(0.0)$ & $43(0.0)$ & $105.9(0.0)$ & $43.3(0.0)$ & $33.7(0.0)$ & - \\
\hline $\begin{array}{l}\text { Nerves and } \\
\text { central nervous } \\
\text { system }\end{array}$ & $63(0.0)$ & $14(0.0)$ & $16(0.0)$ & $59.5(0.0)$ & $13.6(0.0)$ & $16.6(0.0)$ & - \\
\hline $\begin{array}{l}\text { Skin, bone, and } \\
\text { joints system }\end{array}$ & $2(0.0)$ & $1(0.0)$ & $4(0.0)$ & $1.7(0.0)$ & $1.1(0.0)$ & $2.9(0.0)$ & - \\
\hline
\end{tabular}

\section{Adverse events of special interest}

Over the observation period, 2,807 (0.3\%) of the patients had AESI. Two thousand forty-six patients among the unvaccinated group ( $0.4 \%), 469$ patients among the CoronaVac (0.3\%) group, and 292 patients among the Comirnaty group (0.2\%) had AESI over the observation period. The incidence rates for the unvaccinated, CoronaVac, and Comirnaty groups were $59.0(95 \% \mathrm{Cl}$ 56.4-61.5), 39.8 (95\% Cl 36.2-43.4), and 36.4 (95\% Cl 32.2-40.6) per 1,000 person-year respectively. Figure 2 shows the Kaplan-Meier curves illustrating the AESI-free survival patterns by multimorbidity status and vaccination status. Patients with multimorbidity were observed to have a worse AESI-free survival pattern but no substantial differences were identified between 
vaccination status. Figure 3 shows three chord diagrams by vaccination status exemplifying the relative frequencies (represented by ribbon area) of AESI-chronic condition pairings with each color representing a specific AESI. The pairings were similarly patterned across all three groups, suggesting the cooccurrence of specific chronic conditions and AESI are similar between the unvaccinated, those receiving Comirnaty and those receiving CoronaVac.

\section{Cox proportional hazard model}

As shown in Table 2, Model 1 of the Cox proportional hazard regression analysis suggested that patients who received vaccines had a lower risk of AESI [hazard ratio $(\mathrm{HR})=0.66,95 \% \mathrm{Cl} 0.58-0.75$ for Comirnaty and $\mathrm{HR}=0.70,95 \% \mathrm{Cl} 0.63-0.77$ for CoronaVac]. Model 2 suggested that multimorbidity was associated with $63 \%$-increased hazards of $\mathrm{AESI}(\mathrm{HR}=1.63,95 \% \mathrm{Cl}$ 1.51-1.75). Model 3 suggested that no significant interaction between vaccination status and multimorbidity in relation to AESI $(\mathrm{HR}=0.88,95 \% \mathrm{Cl} 0.67-1.15$ for Comirnaty; $\mathrm{HR}=1.03,95 \% \mathrm{Cl} 0.84-1.27$ for CoronaVac). For analyses on sub-categories of $\mathrm{AESI}$, results were largely similar with the main findings (eTable 1 ).

Table 2

Hazard ratios with 95\% confidence intervals $(\mathrm{Cl})$ of adverse events of interest generated from Cox proportional hazard models with inverse probability of treatment weighting

\begin{tabular}{|c|c|c|c|}
\hline & \multicolumn{3}{|l|}{ Hazard ratios $(95 \% \mathrm{Cl})$} \\
\hline & Model 1 & Model 2 & Model 3 \\
\hline \multicolumn{4}{|l|}{ Vaccination status } \\
\hline Unvaccinated & Ref & Ref & Ref \\
\hline Comirnaty & $0.66(0.58,0.75) * \star \star$ & 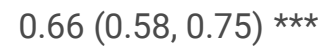 & 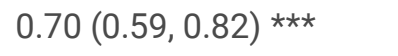 \\
\hline CoronaVac & 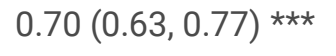 & $0.70(0.63,0.78) * \star \star$ & 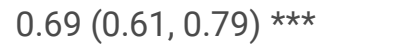 \\
\hline \multicolumn{4}{|l|}{ Multimorbidity status } \\
\hline One chronic condition & - & Ref & Ref \\
\hline Multimorbid & - & $1.63(1.51,1.75) * \star \star$ & 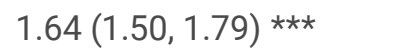 \\
\hline \multicolumn{4}{|l|}{ Interaction } \\
\hline Comirnaty $\mathrm{X}$ multimorbidity & - & & $0.88(0.67,1.15)$ \\
\hline CoronaVac X multimorbidity & - & & $1.03(0.84,1.27)$ \\
\hline \multicolumn{4}{|c|}{ *** $P<0.001$; ** $P<0.01 ; * P<0.05$} \\
\hline $\begin{array}{l}\text { Included independent variab } \\
2+\text { interaction between vacc }\end{array}$ & $\begin{array}{l}\text { 1: vaccination status } \\
\text { us and multimorbidit }\end{array}$ & del 2: Model $1+m \iota$ & dity status; Model 3: Model \\
\hline
\end{tabular}

\section{Sensitivity analysis}

A significant negative interaction between Comirnaty and Charlson Comorbidity Index score ( $\mathrm{HR}=0.72,95 \% \mathrm{Cl} 0.59-0.88)$ was found in the replicated analysis with multimorbidity defined using Charlson Comorbidity Index score (eTable 2). This finding may suggest a weaker association of Comirnaty use and AESI among multimorbid patients with severe chronic conditions compared with those with less severe conditions. No substantial deviations from the main analysis were observed in the findings of a series of other sensitivity analysis (eTable 3 - eTable 6).

\section{Discussion}

We found no evidence of a modified association between vaccination and AESI among those living with multimorbidity compared with those without. This finding was also true for all sub-categories of AESI. Regardless of vaccination status, there is a significantly heightened risk among people with multimorbidity compared with those having only one condition. 
Our results showed a lower risk of AESI among patients receiving the vaccines than among those who did not, even after we excluded patients with a hospitalization record in the past six months from the analyses (eTable 6). This finding may reflect an indication bias whereby patients who decided to get vaccinated were those who had their chronic conditions better controlled even given the same diagnoses ${ }^{16}$. This observation is in line with the official guidelines published by the Hong Kong Government recommending that patients with chronic conditions consult physicians before receiving the vaccine ${ }^{17}$. Consequently, only the chronic disease patients with better managed conditions received the vaccines after self-selection as well as clinicians' screening. Nevertheless, even with this potential bias towards an inverse association of vaccines with AESI, there should be no impact on our key result of no stronger association of vaccines with AESI across multimorbidity status. This is because this indication bias should apply to both multimorbid patients and patients with only one listed condition. If multimorbidity does imposes additional AESI risk increase following vaccination, the test for effect modification (interaction in Model 3) should still be able to detect this risk increase.

These findings largely agree with the existing published data on the safety profile of the two investigated Covid-19 vaccines, suggesting no significant safety signals of an increased risk of AESI overall 6,18 , except a recent study on heightened risk of Bell's palsy following the use of CoronaVac, which is a very rare and self-limiting disease with a high recovery rate within a few months ${ }^{7}$. Nonetheless, current post-marketing research in this regard is still limited and accruing ${ }^{18}$. In fact, to the best of our knowledge, no research has examined the role of multimorbidity in the potential risk elevation of AESI. In a protocol template for electronic healthcare databases monitoring under the vACCine covid-19 monitoring readinESS (ACCESS) project funded by the European Medicines Agency ${ }^{19}$, it was recommended that specific at-risk disease groups be examined individually with multimorbidity excluded from analyses. While this recommended approach may contribute to more specific information about the risk profile of vaccines for specific disease groups, it is far from ideal to disregard the presence of a significant proportion of patients with more than one condition. According to a systematic review, global community prevalence of multimorbidity is estimated at approximately one-third ${ }^{20}$. Any research excluding multimorbid patients has limited generalizability to this significant proportion of populations. As far as we are aware, this is the first post-marketing pharmacovigilance study testing for a potential AESI risk elevation associated with multimorbidity.

Subject to further international research to replicate and verify our results, the implications of this study are important to reassure the public with regard to the widespread concern about vaccine safety among individuals living with multimorbidity who are hesitant towards vaccine uptake ${ }^{21}$. First, the incidence of AESI was rare even among a cohort of 0.88 million, with an incidence rate of 51.5 (95\% Cl 49.6-53.4) per 1,000 person-year. Second, we showed that although multimorbidity was associated with a higher risk of AESI, this association was independent of Covid-19 vaccination. Given the fact that people with multimorbidity have a higher risk of developing life-threatening complications if infected with SARS-CoV-2 ${ }^{22}$, our results should be reassuring that multimorbidity does not impose additional risk of AESI following vaccination. For countries where the infection rate is largely under control and publicly perceived risk of infection is low, this information is highly important to strengthen public confidence in the vaccines and hopefully will boost the uptake rate. Third, as shown in the descriptive statistics, a relatively small proportion of patients received the vaccine in this cohort of chronic disease patient and the absolute risk is very low.

Despite this public health importance, there are several limitations to this study. First, we only had access to public healthcare databases and patients managed in the private sectors were not included. However, previous research has suggested that a vast majority of chronic disease patients in Hong Kong had typically used public services and the number of omitted patients should have limited impact on the results ${ }^{23}$. Second, AESI may be handled in settings beyond public healthcare in the city, such as private sector or overseas. Nevertheless, in terms of number of hospital admissions which are warranted for most of the included AESI, the HA constitutes approximately $80 \%$ of the market share in Hong Kong ${ }^{24}$. Third, residual confounding such as the indication bias observed in the study is probable because the variety of covariates considered in the analysis may not be sufficiently wide subject to data availability. Last, as the population of Hong Kong is predominantly Chinese, replication of the analyses in other world populations is warranted to test for generalizability of the results.

\section{Conclusion}


In this post-marketing pharmacovigilance study of 0.88 million individuals with chronic diseases, we found a low incidence of AESI and no evidence of a modified association between Covid-19 vaccination and AESI by multimorbidity status.

\section{Methods}

\section{Study design}

We adopted a retrospective cohort study design to examine the association between vaccination and the risk of AESI 28-day post-vaccination as well as the effect modification by multimorbidity status.

\section{Data source}

De-identified electronic medical records of patients (aged 16 years or older) were provided by the HA, the sole provider of public inpatient services and a major provider of public outpatient services in Hong Kong. De-identified vaccination records provided by the Department of Health were linked by matching a unique person ID between the two databases. These two sources of data have been used for previous Covid-19 vaccine safety research ${ }^{7}$.

This study was approved by the Institutional Review Board of the University of Hong Kong / Hospital Authority Hong Kong West (UW 21-149 and UW 21-138).

\section{Cohort selection}

The mass Covid-19 vaccination program in Hong Kong was launched on February 23, 2021 for CoronaVac and March 6, 2021 for Comirnaty We retrieved the records of patients who received inpatient or outpatient services provided by the HA during January 1,2018 - July 31, 2021 and selected those ever coded with a diagnosis of any of 20 chronic conditions in the medical records since 2005 based on a widely used list of conditions for multimorbidity operationalization ${ }^{25}$ including hypertension, diabetes mellitus (type 2), severe constipation, depression, cancer, hypothyroidism, chronic pain, asthma, alcohol misuse, chronic pulmonary disease, schizophrenia, rheumatoid arthritis, peptic ulcer disease, cirrhosis, psoriasis, Parkinson's disease, dementia, irritable bowel syndrome, inflammatory bowel disease, and peripheral vascular disease using International Classification of Diseases, Ninth Revision (ICD-9) and International Classification of Primary Care, Second Edition (ICPC-2). Diseases which overlapped with the AESI investigated (based on ICD-9) were not considered. eTable 7 shows the ICD-9 and ICPC-2 codes used to identify the patients. Subsequently, age and sex were used to match the vaccinated individuals with unvaccinated individuals at the ratio of one to three with the first-dose vaccination date of vaccinated individuals mapped to the matched unvaccinated individuals as the index date (February 23, 2021 onwards). We further removed those who died before the index date, were hospitalized on the index date, had chronic disease diagnoses only after the index date, or had AESI records before the index date.

\section{Outcome: adverse events of special interest}

We followed the World Health Organization's Global Advisory Committee on Vaccine Safety (GACVS) ${ }^{26}$ and adopted a list of 30 AESI (please see eTable 8), to define the primary composite outcome of this study using both inpatient and outpatient diagnoses, i.e., time to any AESI from the index date. Observation also ended with 28 days after the index date, death, receiving the second dose, and July 31, 2021 (end of available data), whichever came earliest. Eight sub-categories of the AESI according to GACVS, namely, auto-immune diseases, cardiovascular system diseases, circulatory system diseases, hepato-renal system diseases, nerves and central nervous system diseases, skin and mucous membrane, bone and joints system diseases, respiratory system diseases, and diseases of other systems, were used as the secondary outcomes.

\section{Exposure: vaccination with CoronaVac/Comirnaty}

Receiving CoronaVac and receiving Comirnaty as compared with being unvaccinated were adopted as the exposure of this study. As patients are not allowed to switch between vaccine types because of the centralized booking system managed by the Hong Kong Government, these three categories are mutually exclusive.

\section{Effect modifier: multimorbidity}

Page 8/14 
Multimorbidity was dichotomized as being multimorbid (with two or more listed chronic conditions) versus only one condition.

\section{Multiple vaccination group weighting}

Similar to the inverse probability of treatment weighting method, we used entropy balancing ${ }^{27}$ implemented by the R package 'Weightlt' to assign an optimized set of weights to the patients in the cohort to generate balanced cohorts considering the potential confounding effects of age, sex, and each of the 20 chronic conditions used to identify the cohort ${ }^{27}$. The SMD between the unvaccinated, CoronaVac and Comirnaty groups were examined with the maximum differences (among the three between-group differences) being smaller than 0.1 indicating balance between the three groups 28 .

\section{Statistical analysis}

We implemented a Cox proportional hazard model to examine the association between vaccination and AESI in the weighted cohort. Three models were constructed. First, we included vaccination status only. Second, we further included multimorbidity to examine the association between multimorbidity and AESI. Third, we specified an interaction between vaccination and multimorbidity to test for the differences of the association of vaccination with AESI between multimorbid patients and those living with only one condition. The same analyses were replicated on all sub-categories of AESI as secondary outcomes.

\section{Sensitivity analysis}

A series of sensitivity analyses were conducted to test for the robustness of the results. First, we replicated the main analysis with the 28th day following the index date and date of second dose omitted as observation endpoints. This analysis was to examine any potentially different results arising from including the observation of the second dose. Second, we replicated the analysis on only those who were vaccinated on or before July 3,2021 to allow all patients to have at least 28 days of observation. Third, we replicated the main analysis on those with only ICD-9 diagnoses in our records, with multimorbidity status replaced by the Charlson Comorbidity Index scores ${ }^{29}$ to take into consideration the severity of diseases. Fourth, we replicated the analysis with AESI outcomes defined by inpatient records only and excluded outpatient records to minimize misclassification of follow-up visits in the outpatient setting. Fifth, we replicated the analysis with patients with a hospitalization record within six months prior to the baseline removed.

All analyses were conducted using the R statistical environment (Version 4.1.1, Vienna, Austria). There were no missing data in the medical records. A P-value of 0.05 or below was considered indicative of statistical significance.

\section{Data availability}

Data will not be available for others as the data custodians have not given permission.

\section{Declarations}

\section{Competing interests}

FTTL has been supported by the RGC Postdoctoral Fellowship under the Hong Kong Research Grants Council and has received research grants from the Food and Health Bureau of the Government of the Hong Kong Special Administrative Region, outside the submitted work. CSLC has received grants from the Food and Health Bureau of the Hong Kong Government, Hong Kong Research Grant Council, Hong Kong Innovation and Technology Commission, Pfizer, IQVIA, and Amgen; and personal fees from PrimeVigilance; outside the submitted work. EYFW has received research grants from the Food and Health Bureau of the Government of the Hong Kong Special Administrative Region, and the Hong Kong Research Grants Council, outside the submitted work. XL has received research grants from the Food and Health Bureau of the Government of the Hong Kong Special Administrative Region; research and educational grants from Janssen and Pfizer; internal funding from the University of Hong Kong; and consultancy fees from Merck Sharp \& Dohme, unrelated to this work. EWYC reports honorarium from Hospital Authority; and grants from Research Grants Council (RGC, Hong Kong), Research Fund Secretariat of the Food and Health Bureau, National Natural Science Fund of China, Wellcome Trust, Bayer, Bristol-Myers Squibb, Pfizer, Janssen, Amgen, Takeda, and Narcotics Division of the Security Bureau of the Hong Kong Special Administrative Region, outside the submitted work. 
ICKW reports research funding outside the submitted work from Amgen, Bristol-Myers Squibb, Pfizer, Janssen, Bayer, GSK, Novartis, the Hong Kong Research Grants Council, the Food and Health Bureau of the Government of the Hong Kong Special Administrative Region, National Institute for Health Research in England, European Commission, and the National Health and Medical Research Council in Australia; has received speaker fees from Janssen and Medice in the previous 3 years; and is an independent non-executive director of Jacobson Medical in Hong Kong. All other authors declare no competing interests.

\section{Author contributions}

FTTL had the original idea for the study, constructed the study design and the analytic plan, and wrote the first draft of the manuscript. LH extracted data and performed statistical analysis. FTTL cross-checked the results. CSLC, EYFW, XL, CKHW, EWWC, TTM, HL, EWYC, and ICKW provided critical input to the analyses, design, and discussion. DHL assisted with the literature review. JCNL assisted with formatting the figures. EYFW, CSLC, and ICKW have accessed and verified the data used in the study. ICKW is the principal investigator and provided oversight for all aspects of this project. All authors contributed to the interpretation of the analysis, critically reviewed, and revised the manuscript, and approved the final manuscript as submitted. All authors had full access to all the data in the study and had final responsibility for the decision to submit for publication.

\section{Acknowledgements}

This study was funded by a research grant from the Food and Health Bureau, The Government of the Hong Kong Special Administrative Region (reference COVID19F01). We thank members of the Expert Committee on Clinical Events Assessment Following COVID-19 Immunization for case assessment and colleagues from the Drug Office of the Department of Health and from the Hospital Authority for providing vaccination and clinical data.

\section{References}

1. Kwok, K. O. et al. Psychobehavioral responses and likelihood of receiving COVID-19 vaccines during the pandemic, Hong Kong. Emerging infectious diseases 27, 1802-1810 (2021).

2. Montgomery, J. et al. Myocarditis following immunization with mRNA COVID-19 vaccines in members of the US military. JAMA Cardiology (2021) doi:10.1001/jamacardio.2021.2833.

3. de Simone Giovanni, Stranges, S. \& Gentile, I. Incidence of cerebral venous thrombosis and COVID-19 vaccination: possible causal effect or just chance? European Heart Journal - Cardiovascular Pharmacotherapy 7, e77-e78 (2021).

4. Takuva, S. et al. Thromboembolic Events in the South African Ad26.COV2.S Vaccine Study. New England Journal of Medicine 385, 570-571 (2021).

5. Østergaard, S. D., Schmidt, M., Horváth-Puhó, E., Thomsen, R. W. \& Sørensen, H. T. Thromboembolism and the OxfordAstraZeneca COVID-19 vaccine: side-effect or coincidence? The Lancet 397, 1441-1443 (2021).

6. Li, X. et al. Characterising the background incidence rates of adverse events of special interest for covid-19 vaccines in eight countries: multinational network cohort study. BMJ 373, (2021).

7. Wan, E. Y. F. et al. Bell's palsy following vaccination with mRNA (BNT162b2) and inactivated (CoronaVac) SARS-CoV-2 vaccines: a case series and nested case-control study. The Lancet Infectious Diseases (2021) doi:10.1016/S14733099(21)00451-5.

8. Barnett, K. et al. Epidemiology of multimorbidity and implications for health care, research, and medical education: a crosssectional study. Lancet (London, England) 380, 37-43 (2012).

9. Lai, F. T. T. et al. Multimorbidity in middle age predicts more subsequent hospital admissions than in older age: A nine-year retrospective cohort study of 121,188 discharged in-patients. European Journal of Internal Medicine 61, 103-111 (2019).

10. Lai, F. T. T. et al. Sociodemographic moderation of the association between depression and stroke incidence in a retrospective cohort of 0.4 million primary care recipients with hypertension. Psychological Medicine 1-9 (2020) doi:10.1017/S0033291720001920.

Page $10 / 14$ 
11. Revon-Riviere, G. et al. The BNT162b2 mRNA COVID-19 vaccine in adolescents and young adults with cancer: A monocentric experience. European journal of cancer 154, 30-34 (2021).

12. Monin, L. et al. Safety and immunogenicity of one versus two doses of the COVID-19 vaccine BNT162b2 for patients with cancer: interim analysis of a prospective observational study. The Lancet. Oncology 22, 765-778 (2021).

13. Tanriover, M. D. et al. Efficacy and safety of an inactivated whole-virion SARS-CoV-2 vaccine (CoronaVac): interim results of a double-blind, randomised, placebo-controlled, phase 3 trial in Turkey. The Lancet 398, 213-222 (2021).

14. Polack, F. P. et al. Safety and efficacy of the BNT162b2 mRNA covid-19 vaccine. New England Journal of Medicine 383 , 2603-2615 (2020).

15. Hong Kong Government. COVID-19 Vaccination Programme. https://www.covidvaccine.gov.hk/en/vaccine (2021).

16. Dagan, N. et al. BNT162b2 mRNA Covid-19 vaccine in a nationwide mass vaccination setting. New England Journal of Medicine 384, 1412-1423 (2021).

17. Centre for Health Protection. Interim guidance notes on common medical diseases and COVID-19 vaccination in primary care settings. (2021).

18. Wu, Q. et al. Evaluation of the safety profile of COVID-19 vaccines: a rapid review. BMC Medicine 19, 173 (2021).

19. Sturkenboom, M. Coverage of COVID-19 vaccines in electronic healthcare databases: a protocol template from the ACCESS project. (2021).

20. Nguyen, H. et al. Prevalence of multimorbidity in community settings: A systematic review and meta-analysis of observational studies. Journal of Comorbidity 9, 2235042X19870934 (2019).

21. Wagner, A. L. et al. Vaccine hesitancy and concerns about vaccine safety and effectiveness in Shanghai, China. American Journal of Preventive Medicine 60, S77-S86 (2021).

22. Chung, G. K.-K. et al. Differential impacts of multimorbidity on COVID-19 severity across the socioeconomic aadder in Hong Kong: A syndemic perspective. International journal of environmental research and public health 18, (2021).

23. Yeoh, E.-K. et al. An evaluation of universal vouchers as a demand-side subsidy to change primary care utilization: A retrospective analysis of longitudinal services utilisation and voucher claims data from a survey cohort in Hong Kong. Health Policy 124, 189-198 (2020).

24. Leung, G. M., Tin, K. Y. K. \& O'Donnell, O. Redistribution or horizontal equity in Hong Kong's mixed public-private health system: a policy conundrum. Health Economics 18, 37-54 (2009).

25. Tonelli, M. et al. Methods for identifying 30 chronic conditions: application to administrative data. BMC Medical Informatics and Decision Making 15, 1-11 (2015).

26. World Health Organization. Background paper on Covid-19 disease and vaccines: prepared by the Strategic Advisory Group of Experts (SAGE) on immunization working group on COVID-19 vaccines, 22 December 2020. (2020).

27. Zhao, Q. \& Percival, D. Entropy balancing is doubly robust. Journal of Causal Inference 5, 20160010 (2017).

28. Lau, W. C. Y. et al. Association between dabigatran vs warfarin and risk of osteoporotic fractures among patients with nonvalvular atrial fibrillation. JAMA 317, 1151-1158 (2017).

29. Brilleman, S. L. \& Salisbury, C. Comparing measures of multimorbidity to predict outcomes in primary care: A cross sectional study. Family Practice (2013) doi:10.1093/fampra/cms060.

\section{Figures}




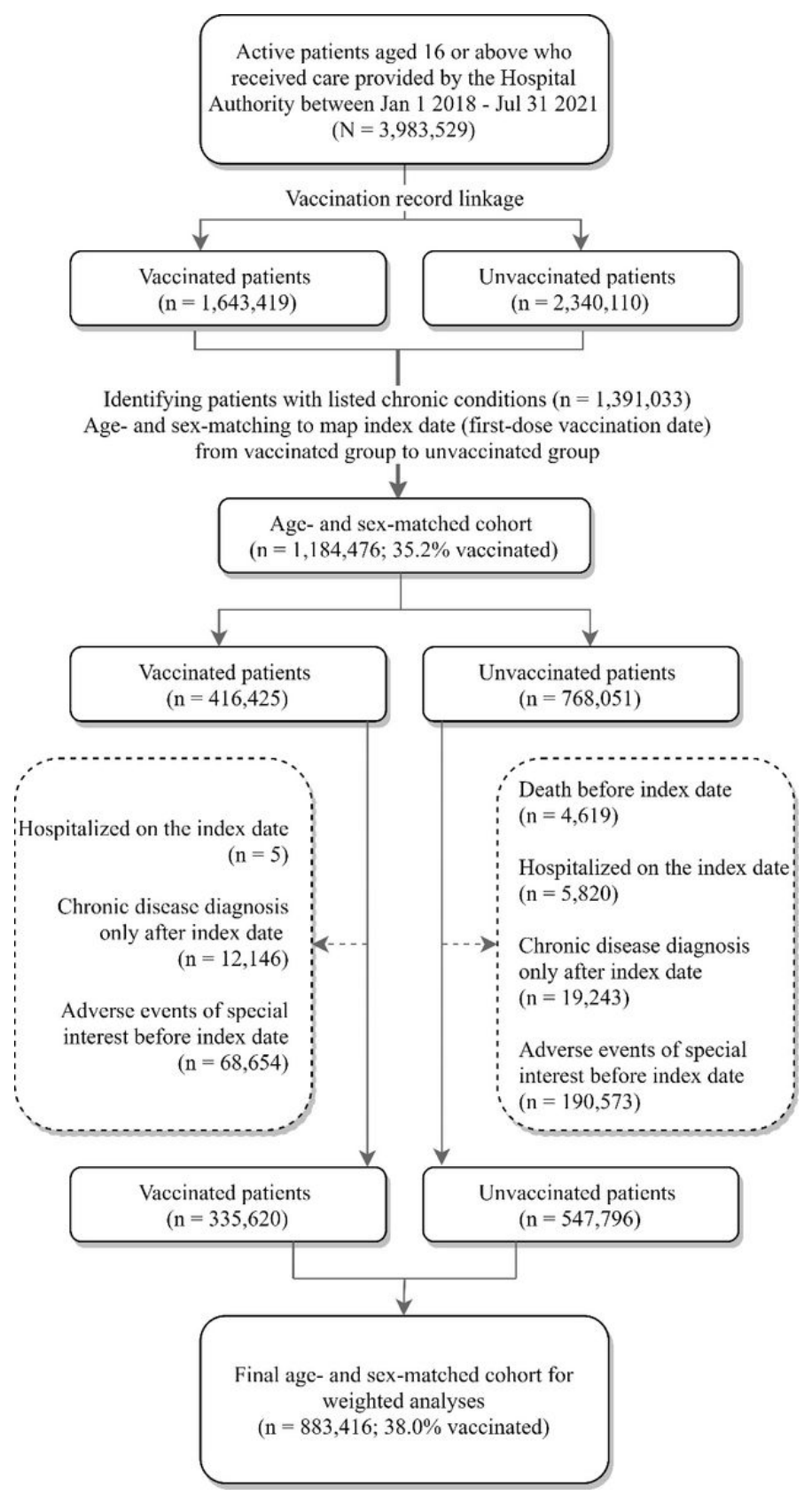

Figure 1

Flow chart of cohort selection 

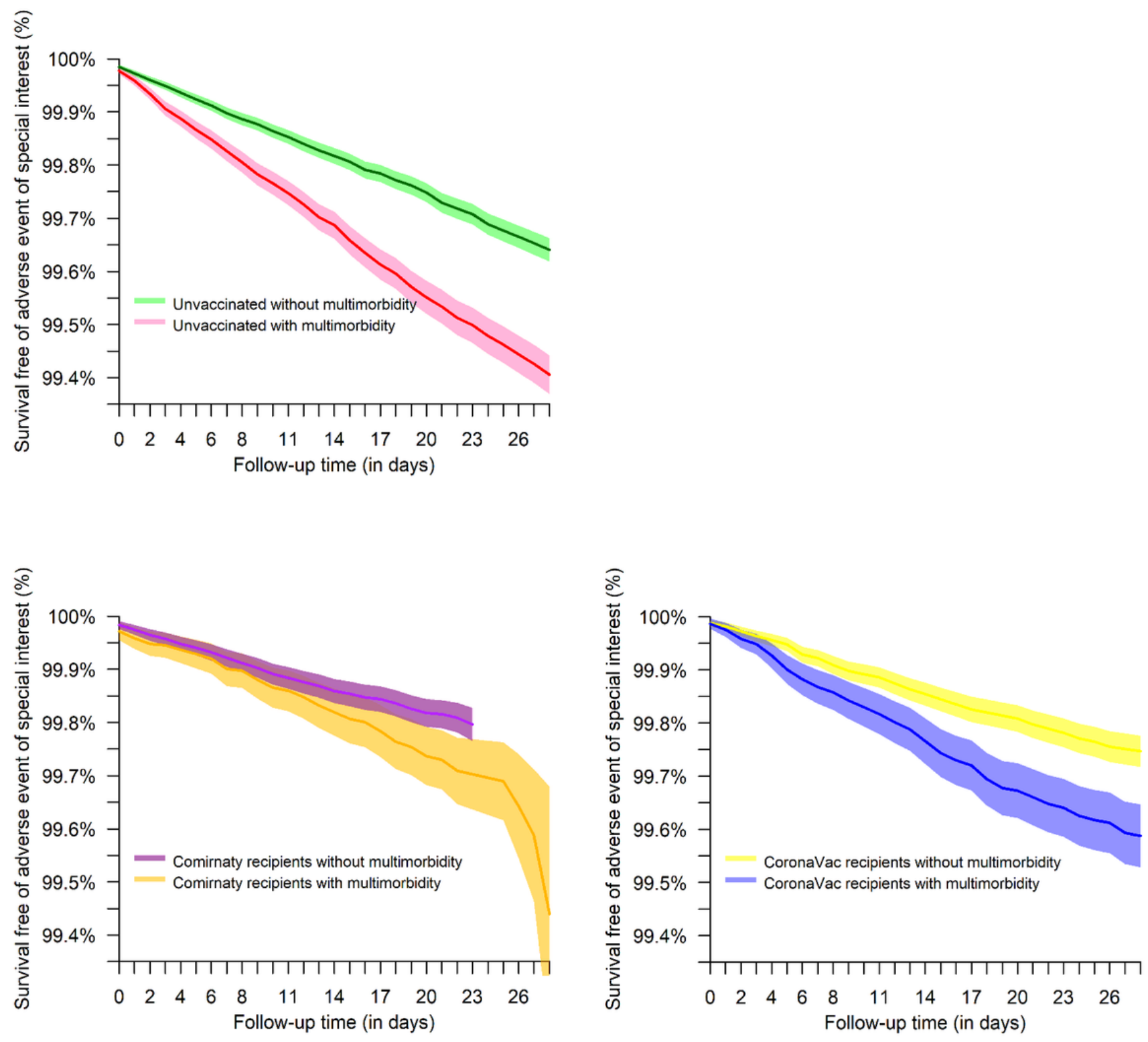

\section{Figure 2}

Kaplan-Meier curves (95\% confidence interval represented by shaded area) showing adverse event of special interest-free survival patterns by multimorbidity and vaccination statuses 


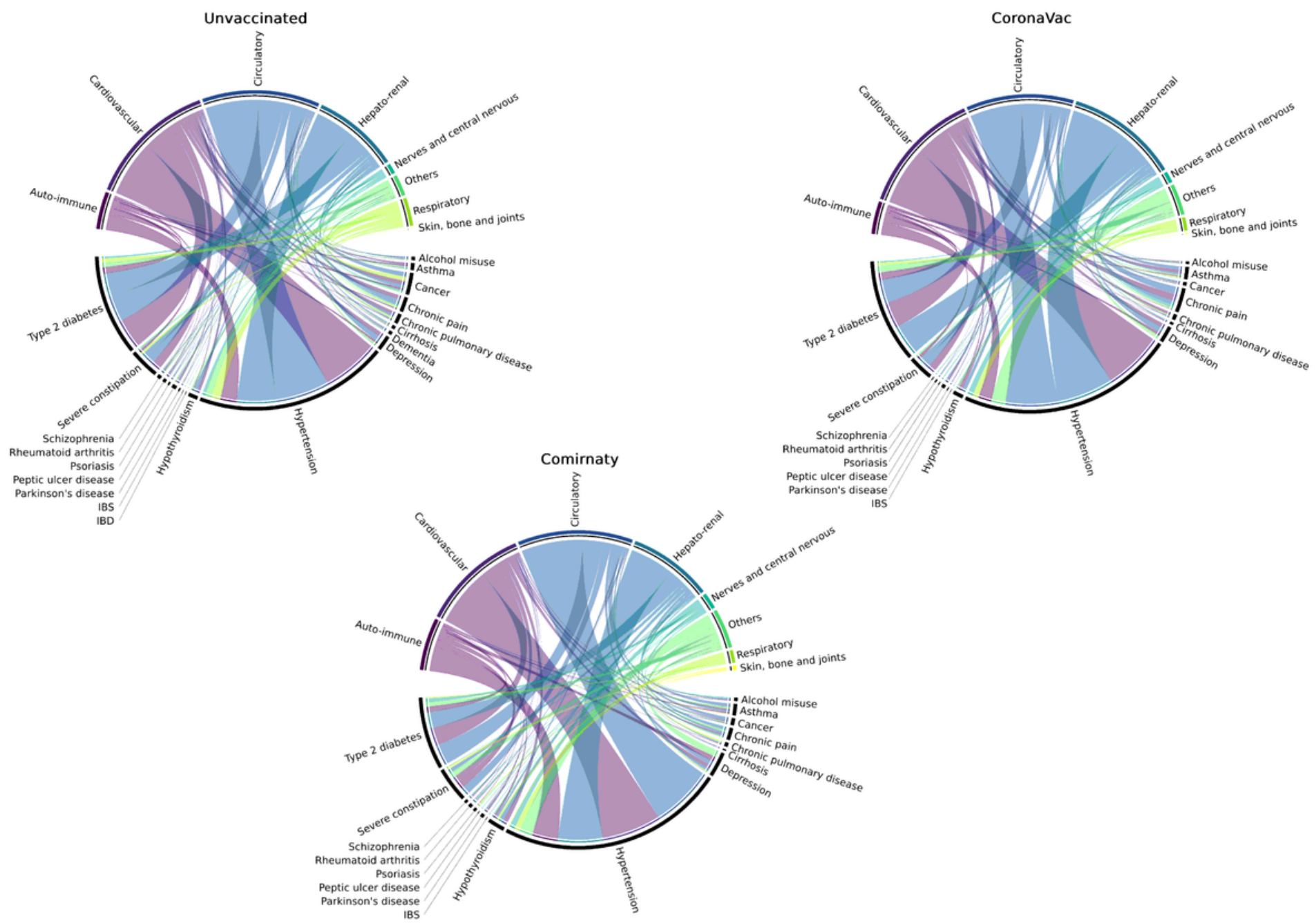

Figure 3

Chord diagrams showing the relative frequencies of the cooccurrence of specific chronic disease (lower arc) and specific adverse events of special interest (upper arc) by vaccination status. The larger the area of the chord linking between a chronic condition and an adverse event of special interest, the more frequently observed the cooccurrence of them. IBS = Irritable bowel syndrome; IBD = Inflammatory bowel disease.

\section{Supplementary Files}

This is a list of supplementary files associated with this preprint. Click to download.

- Supplementarymaterials.pdf 